\title{
Hepatitis B Virus Infection and Anti-HBc (Total) Positivity in CKD Patients before Dialysis
}

\author{
Fareha Jesmin Rabbi ${ }^{1}$, Md Morshed Alam ${ }^{2}$, Kamar Rezwan $^{3}$, Rosy Sultana ${ }^{4}$ \\ Received: May 10, 2016 Accepted: August 7, 2016 \\ doi: http://dx.doi.org/10.3329/jemc.v6i3.29678
}

\begin{abstract}
Background: $C K D$ patients are associated with $H B V$ infection both as a cause and complication of treatment. CKD patients before starting dialysis therapy are considered as a high risk group because of impaired immune response compared with healthy individuals and also other risk factors related with treatment and management. Only HBsAg marker does not always follow the presence or absence of $\mathrm{HBV}$ infection. Anti-HBc (total) alone positivity indicates previous exposure to $H B V$ infection, window period and even after reactivation of resolved $H B V$ infection. In some cases only anti-HBc positivity is interpreted as possible chronic low dose HBV infection (chronic carriage). Predialytic CKD patients were tested with three serological markers [HBsAg, anti-HBC (total) and anti-HBs] for screening HBV infection. Proper diagnosis before dialysis and knowing the infection status would help both the patient and doctor to choose proper treatment approach. Objective: This cross-sectional study was done in the CKD patients before starting dialysis therapy to find out the $H B V$ infection and to evaluate the infection by minimal serological markers as for screening. Materials and Methods: A total of 211 patients with chronic kidney disease stage five $(C K D-V)$ before starting dialysis therapy were included as subjects of this cross-sectional study. Among the CKD patients HBsAg was tested to see the prevalence. Other serological markers, i.e., anti-HBc (total) and anti-HBs were tested in combination with HBsAg in 89 randomly selected patients among the subjects. The patients were also tested for anti-HCV to assess co-infection. After collecting all the data of different test results analyses were done by SPSS version 15.0. Results: Among total study population 10 (4.7\%) patients were found HBsAg positive. No patient was found positive for both HBsAg and anti-HCV. Among the 89 CKD patients only 2 (2.2\%) patients were HBsAg positive, and only one patient (0.9\%) was found positive for both anti-HBC and anti-HCV. Of them, a total of $22(24.7 \%)$ patients were anti-HBs positive, and 35 (39.3\%) patients were anti-HBc (total) positive. Of the three markers anti-HBc (total) alone positivity were in 20 (22.5\%) patients. Conclusion: Data indicate a large proportion of HBV infected patients were underdiagnosed by usual screening method by HBsAg in our country. The finding of anti-HBc (total) alone cannot be clearly interpreted in terms of patient prognosis or infectivity. Patients are simply regarded as potentially infectious. Due to this uncertainty, different countries employ different procedures when faced anti-HBc alone findings. In some countries including ours the test is not performed. Since a substantial number of CKD patients with HBV infection have this anti$H B c$ (total) positivity, standard screening procedures and precautions should be taken in blood donation, hemodialysis and for other invasive procedures to prevent transmission of infection.
\end{abstract}

Key words: HBV; HBsAg; Anti-HBc (total); Anti-HBs; Dialysis; Window period

J Enam Med Col 2016; 6(3): 128-133

1. Associate Professor, Department of Clinical Immunology, National Institute of Kidney Diseases and Urology (NIKDU)

2. Assistant Professor, Department of Biochemistry, NIKDU

3. National Professional Officer, HIV and Vector borne Disease, WHO, Bangladesh

4. Associate Professor, Department of Immunology, Bangladesh University of Health Sciences, Dhaka

Correspondence Fareha Jesmin Rabbi, Email: fjesminr@yahoo.com 


\section{Introduction}

Chronic kidney disease (CKD) is a worldwide problem with increasing incidence and prevalence of $10.3-13.7 \%$ in different countries. ${ }^{1-3}$ It is frequently associated with liver diseases. Hepatitis B virus (HBV) infection as one of the most common causes of liver disease can cause $\mathrm{CKD}$ and $\mathrm{CKD}$ patients can acquire HBV infection during the course of management. Management of the CKD patients associated with these infections is coupled with adverse effects and higher rate of morbidity and mortality. ${ }^{4,5}$ These infections are transmitted primarily through the parenteral route. Sexual and vertical routes also have some role in transmission. Some studies have shown that nosocomial transmission is not rare. CKD patients are at increased risk of acquiring $\mathrm{HBV}$ infection as a result of nosocomial spread or exposure to infected blood and blood products. ${ }^{6}$ While the risk of transmission of these two viruses has been considerably reduced in developed countries owing to increased screening procedures ${ }^{7-9}$, the problem is not properly addressed in developing countries like Bangladesh. Because of common modes of transmission, HBV infection may co-exist with HCV infection and is relatively high in transfusion recipients. ${ }^{10-12}$ The prevalence of $\mathrm{HBV}$ infection (HBsAg seropositive) among patients on maintenance hemodialysis in the developed world is currently low $(0-10 \%)$ but remains higher (2-20\%) in developing countries. ${ }^{4}$ CKD patients with HBV infection may be more likely to develop chronic infection once exposed

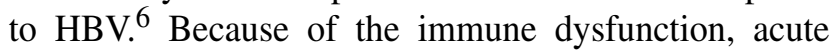
$\mathrm{HBV}$ infection is often mild or asymptomatic in CKD patients, and in contrast to normal adults, the majority of them become chronic carriers due to impaired viral clearance. $^{13,14}$

The antibody response to HBV vaccine in CKD patients is reduced and declines logarithmically with time. ${ }^{15}$ CKD patients ultimately undergo end stage renal therapy like dialysis for their treatment and survival. Risk factors for the infections are more in dialysis period than in predialytic stages. For this reason the CKD patients should be properly diagnosed knowing the infection status before dialysis which would help both the patient and doctor to choose the proper way of treatment to prevent nosocomial transmission and to use properly screened blood product by sterile technique.

There are different serological and molecular markers for the diagnosis of HBV infection and to assess the immunity against the infection. Most commonly in endemic areas, HBV chronic carriage stage with HBsAg too low to be detected is recognized by the presence of anti-HBc (total) as the only serological marker referred to as 'anti-HBc alone' or 'isolated anti$\mathrm{HBc}$ ' ${ }^{16}$ So, for rapid diagnosis and screening purpose minimal serological markers of $\mathrm{HBV}$ infection like HBsAg, anti-HBc (total) and anti-HBs may be done to comply with time and cost and to know the infection immune status to prevent transmission. We should have knowledge about the existence of the HBV infection in CKD patients before dialysis as immune response is reduced in CKD patients compared to healthy individuals and the patient may get infection during course of management. A very few studies are available regarding prevalence of $\mathrm{HBV}$ in $\mathrm{CKD}$ patients before dialysis. ${ }^{17}$ In this study it has been attempted to determine the prevalence of HBsAg in the predialytic CKD patients and minimal serological markers, i.e., $\mathrm{HBsAg}$, anti-HBc (total) and anti-HBs were tested to determine $\mathrm{HBV}$ infection status and immune stage of the infected or vaccinated patients. This will help in reducing the transmission of infection, and thereby taking further necessary action.

\section{Materials and Methods}

This cross-sectional study was carried out during the period from July 2011 to June 2012. A total of 211 patients with CKD stage five (CKD-V) [Estimated glomerular filtration rate (eGFR) $<15 \mathrm{~mL} / \mathrm{min} / 1.73 \mathrm{~m}^{2}$ for $\geqslant 3$ months] before starting dialysis therapy were included in this study. Patients with CKD admitted in the Department of Nephrology in National Institute of Kidney Diseases and Urology hospital were tested and included as subjects of this study. CKD stage five was assessed according to the relevant history and based on age, sex and serum creatinine value. According to Kidney Disease Outcome Quality Initiative (KDOQI) guideline patients with estimated GFR $<15$ $\mathrm{mL} / \mathrm{min} / 1.73 \mathrm{~m}^{2}$ for $\geqslant 3$ months was considered as CKD-V. ${ }^{18}$ Estimated GFR was calculated from serum creatinine level by using Modification of Diet in Renal Disease (MDRD) prediction equation: GFR $\left(\mathrm{mL} / \mathrm{min} / 1.73 \mathrm{~m}^{2}\right)=186 \times(\mathrm{Scr})^{-1.154} \times(\text { Age })^{-0.203} \times$ (0.742 if female).

Among the CKD patients HBV infection markers like $\mathrm{HBsAg}$, anti-HBc (total) and anti-HBs were tested using ELISA method (Human GmbH-Germany) to assess the hepatitis B virus infection stages and immune 
condition of the infected or vaccinated patients. All predialytic CKD patients were screened for HBsAg. Among all study subjects 89 predialytic CKD patients were taken randomly and tested in addition for anti-HBs and anti-HBc (total). Antibody to HCV was tested to see co-infection. Only 89 subjects were managed for testing the additional serological markers due to fund constraint. HBV infection and HBV vaccination stages were assessed and analyzed. After collecting all the data of different test results analyses were done by SPSS version 15.0.

\section{Results}

Total 211 CKD patients before starting dialysis therapy were included in the study. Of them 121 were male and 90 were female with mean age 43.93 \pm 15.68 years. All patients were tested for HBsAg. Among them 10 (4.7\%) patients were found positive for HBsAg and 201 (95.3\%) patients were HBsAg negative.

Among all predialytic CKD patients 89 CKD patients were included randomly to test the serological markers of HBV infection. HBsAg, anti$\mathrm{HBs}$ and anti-HBc (total) were done to know the infection status whether the patient had no infection or got cured of HBV infection or was in window period. In addition, the patients might have old infection or chronic infection or acute infection or the patient might get HBV vaccination.

Among the 89 CKD patients only $2(2.2 \%)$ were HBsAg positive, $22(24.7 \%)$ patients were anti-HBs positive and $35(39.3 \%)$ patients were anti-HBc (total) positive. All the serological markers were analyzed combined to detect CKD patients with or without $\mathrm{HBV}$ infection in pre-dialysis stage into six categories: no HBV infection (HBsAg -ve, anti$\mathrm{HBc}-\mathrm{ve}$, anti-HBs -ve), acute HBV infection (incubation period)/recent vaccination ( $\mathrm{HBsAg}+\mathrm{ve}$, anti-HBc-ve, anti-HBs - ve), chronic/acute infection (HBsAg +ve, anti-HBc +ve, anti-HBs -ve), old cured infection (HBsAg -ve, anti-HBc +ve, antiHBs +ve), HBV infected patient with window period/old infection without protective antibody/ chronic carriage anti-HBc alone (HBsAg -ve, anti$\mathrm{HBc}+\mathrm{ve}$, anti-HBs -ve) and patients had vaccination (HBsAg -ve, anti-HBc - ve, anti-HBs $+v e$ ). CKD patients with an isolated positive test for
anti-HBc IgG or anti-HBc (total) are called anti-HBc alone. Among the 89 CKD patients only one patient $(0.9 \%)$ was found positive for both anti-HBc (total) and anti-HCV. No patient was found positive for both HBsAg and anti-HCV. The following table shows analysis of the results of three serological tests (HBsAg, anti-HBc [total] and anti-HBs) of $\mathrm{HBV}$ infection and vaccination.

Table I: CKD patients having no HBV infection or having different stages of HBV infection and HBV vaccination by only three serological markers: $\mathrm{HBsAg}$, anti-HBc (total) and anti-HBs

\begin{tabular}{|c|c|c|c|}
\hline $\begin{array}{l}\text { HBV infection stages and } \\
\text { vaccination }\end{array}$ & $\begin{array}{l}\text { HBV seromarkers } \\
\text { (HBsAg, anti-HBc } \\
\text { [total], anti-HBs) }\end{array}$ & Frequency & Percentage \\
\hline No HBV infection & $\begin{array}{l}\text { HBsAg-ve, anti-HBs-ve, } \\
\text { anti-HBc-ve }\end{array}$ & 45 & 50.6 \\
\hline $\begin{array}{l}\text { Acute infection (incubation } \\
\text { period)/recent vaccination }\end{array}$ & $\begin{array}{l}\mathrm{HBsAg}+\mathrm{ve}, \text { anti-HBs-ve, } \\
\text { anti-HBc-ve }\end{array}$ & 2 & 2.2 \\
\hline Old cured infection & $\begin{array}{l}\mathrm{HBsAg}-\mathrm{ve} \text {, anti-HBs +ve, } \\
\text { anti-HBc +ve }\end{array}$ & 15 & 16.9 \\
\hline $\begin{array}{l}\text { Window period/old infection } \\
\text { without protective } \\
\text { antibody/chronic carriage anti- } \\
\mathrm{HBc} \text { alone }\end{array}$ & $\begin{array}{l}\text { HBsAg-ve, anti-HBs -ve, } \\
\text { anti-HBc +ve }\end{array}$ & 20 & 22.5 \\
\hline Previously vaccinated & $\begin{array}{l}\mathrm{HBsAg}-\mathrm{ve} \text {, anti-HBs +ve, } \\
\text { anti-HBc-ve }\end{array}$ & 7 & 7.9 \\
\hline Total CKD patients & & 89 & 100.0 \\
\hline
\end{tabular}

No patient was found positive for the category of chronic/acute infecton (HBsAg +ve, anti-HBc +ve and anti-HBs -ve).

The patients who developed protective antibody anti-HBs against hepatitis $B$ virus became immune and noncontagious. The two groups; old cured infection (HBsAg -ve, anti-HBc +ve, anti-HBs +ve) and previously vaccinated patients (HBsAg -ve, anti-HBc -ve, anti-HBs $+v e)$ developed anti-HBs and immunity. So, among total CKD patients about $24 \%$ developed protective antibody against $\mathrm{HBV}$.

\section{Discussion}

Hepatitis is one of the most common causes of mortality in CKD patients ranking third in number after cardiovascular disease and infection. Prevention and treatment of hepatitis gain more importance in the treatment of CKD patient. ${ }^{19-21}$ In our country where both hepatitis and CKD are endemic it can be considered that exposure of CKD patients to 
hepatitis virus is natural. Of the total HBV infected cases and carriers, 95\% live in the developing countries with variation in infection rate from country to country. In the Middle-East and Indian sub-continent, HBV infection is of intermediate endemicity with chronic HBV carriage rate of $2-5 \%$ among general population. $^{22}$ In Bangladesh, there is paucity of information on the prevalence of $\mathrm{HBV}$ and $\mathrm{HCV}$ infections among general population and majority of the previous studies were conducted in selected group of people with higher risk factors such as blood donors, drug addicts, commercial sex workers (CSWs) or hospitalized patients. ${ }^{23-27}$ However, a report showed 5.5\% HBsAg positivity among the general population living in Savar, a semi-urban area on the outskirts of Dhaka. ${ }^{28}$ According to another study ${ }^{29}$ conducted by icddr,b at Kamalapur, Dhaka 1997 participants (general population) were screened for $\mathrm{HBsAg}$, anti-HBc and anti-HCV. HBV-seropositivity (HBsAg positive and anti-HBc positive) was documented in 582 (29\%) participants. Among them $14(0.7 \%)$ were positive for HBsAg, 452 (22.6\%) positive for anti-HBc and 116 (5.8\%) for both HBsAg and anti-HBc. So, the HBsAg prevalence was of $6.5 \%$ among their study population. Four $(0.2 \%)$ participants were positive for anti-HCV and another five $(0.3 \%)$ for both anti-HBc and anti$\mathrm{HCV}^{29}$ In the present study $10(4.7 \%)$ patients were found HBsAg positive among 211 predialytic CKD patients, which is comparable with the previous studies in Dhaka ${ }^{28,29}$ and lies within the range of $2-7 \%$, reported by previous studies from selective and general population. $^{23-29}$ Out of the total population only 89 predialytic CKD patients were tested for anti-HBc and anti-HBs due to fund constraint. Among the 89 CKD patients only $2(2.2 \%)$ patients were HBsAg positive, $22(24.7 \%)$ patients were anti-HBs positive, and 35 (39.3\%) patients were anti-HBc (total) positive. No patient was found positive for both HBsAg and antiHBc. So, a total of 37 (41\%) CKD patients have been found seropositive (HBsAg positive and anti-HBc positive) for $\mathrm{HBV}$ infection which is higher than the total seropositivity [582 (29\%)] percentage found in general population in another study. ${ }^{29}$ Only anti-HBc positive percentage $(39.3 \%)$ was found higher in CKD patients than in general population $(22.6 \%) .{ }^{29}$

As the dialysis patients are higher risk group to get the infections, there may be discrepancy in pre-dialysis and dialysis period regarding these infections. In Bangladesh, around $12 \%$ of patients on maintenance hemodialysis were serologically positive for hepatitis B virus infection. ${ }^{30}$ In India, HBV prevalence was $8.8 \%$ and $14.2 \%$ in predialysis and hemodialysis group respectively. ${ }^{31,32}$ In Turkey, prevalence of HBV was $10.5 \%$ and $4.9-6.5 \%$ in predialysis and hemodialysis patients respectively. ${ }^{17,33}$ In another study ${ }^{34}$ in Bangladesh, researchers included 25 predialytic patients and 63 maintenance hemodialysis patients and $\mathrm{HBsAg}$ positivity was more $(16 \%)$ in predialysis compared to $1.6 \%$ in hemodialysis period. Our data of $\mathrm{HBsAg}$ positivity differ from above study in predialytic CKD patients. ${ }^{34}$ Improvements in the national vaccination programs, reduction of transfusion numbers due to erythropoietin administration and implementation of compulsory blood donor screening have reduced the number of HBV infection. But still due to diminished immune response and lack of thorough blood screening HBV infection remains a major concern in HD centers. ${ }^{35}$

HBV prevalence by HBsAg seromarker has been evaluated in many studies and also in present study. But presence or absence of only HBsAg marker does not always follow the presence or absence of $\mathrm{HBV}$ infection. Here 89 predialytic CKD patients were tested and analyzed by other serologic markers for HBV, anti$\mathrm{HBc}$ and anti-HBs in addition to HBsAg. Only three serological markers were included to analyze the HBV infection for screening purpose to make it cost-effective and to prevent transmission of infection. Cured condition having protective antibody (anti-HBs) against HBV reflect immune stage and infected patients without anti-HBs were non-immune. All three serological markers were analyzed combined to detect CKD patients with or without HBV infection into six categories: no HBV infection (50.6\%), acute HBV infection (incubation period) or recent vaccination (2.2\%), old cured infection (16.9\%), HBV infected patient in window period or old infection (without protective antibody) or chronic carriage anti-HBc alone $(22.5 \%)$ and patients with previous vaccination (7.9\%). No patient was found to have chronic or acute HBV infection. To diagnose occult $\mathrm{HBV}$ infection ${ }^{16} \mathrm{HBV}$ DNA should have been done in addition to the present seromarkers for treatment and prognosis. HBV DNA is a costly molecular test and we could not afford it.

A total of 35 (39.3\%) CKD patients were found anti$\mathrm{HBc}$ (total) positive. Of them 20 (22.5\%) were with anti-HBc (total) alone positive of the three sero- 
markers. Serological recovery from HBV infection with anti-HBs positivity usually signifies clearance of viremia and complete resolution of hepatocellular injury. In immunocompetent patients anti-HBs persists for decades and generally prevents reinfection. However, even after serological recovery, HBV may persist as an occult infection. Reactivation of $\mathrm{HBV}$ infection may occur in a known asymptomatic HBsAg carrier or in patient with occult HBV or rarely with resolved HBV infection in immunosuppressed patients. ${ }^{36,37} \mathrm{CKD}$ patients positive only for anti-HBc (total) indicate those HBV infected patients who were in window period or had old infection (without protective antibody) or chronic carriage with anti- $\mathrm{HBc}$ alone. Though anti-HBc alone in case of 'core window' usually lasts for a few weeks in majority of people who test positive for anti-HBc alone, this finding may persist for years to decades without formation of protective antibody. It may indicate previous HBV infection which occurred years to decades ago when anti-HBs disappears before anti-HBc is detected. In some cases these findings are interpreted as possible chronic low dose HBV infection (chronic carriage) or atypical infection with HBV mutants or patients with circulating HBV DNA with undetectable HBsAg. ${ }^{38,39}$

Some individuals with 'anti-HBc alone' carry HBV in their serum, their proportion varies greatly between $0.2 \%$ in blood donors and $47 \%$ in intravenous drug abusers. ${ }^{38}$ In HBV endemic areas, anti-HBc alone or isolated anti-HBc positive patient may have $\mathrm{HBV}$ chronic carriages stage with HBsAg too low to be detected and recognized by the presence of anti-HBc as the only serological marker. ${ }^{16,35}$

So the finding of anti-HBc alone cannot be clearly interpreted in terms of patient prognosis or infectivity. Patients are simply regarded as potentially infectious. Due to this uncertainty different countries employ different procedures when faced anti-HBc alone findings. In case of blood donation, many countries including United States test blood for anti-HBc (total) and discard the blood from anti-HBc alone positive donors. ${ }^{35}$ This test is not performed in some countries including ours. Since individuals with anti-HBc alone are considered potentially infectious and a substantial number of CKD patients with HBV infection have this anti-HBc alone positivity, standard screening procedures and precautions should be taken in blood donation, hemodialysis and for other invasive procedures to prevent transmission of infection.

\section{References}

1. Ayodele OE, Alebiosu CO. Burden of chronic kidney disease: an international perspective. Adv Chronic Kidney Dis 2010; 17: 215-224.

2. Foley RN. Temporal trends in the burden of chronic kidney disease in the United States. Curr Opin Nephrol Hypertens 2010; 19: 273-277.

3. Stengel B, Billon S, Van Dijk PC, Jager KJ, Dekker FW, Simpson $\mathrm{K}$ et al. Trends in the incidence of renal replacement therapy for end-stage renal disease in Europe, 1990-1999. Nephrol Dial Transplant 2003; 18: 1824-1833.

4. Fabrizi F, Messa P, Martin P. Hepatitis B virus infection and the dialysis patient. Semin Dial 2008; 21: 440-446.

5. Molino C, Fabbian F, Cozzolino M, Longhini C. The management of viral hepatitis in CKD patients: an unresolved problem. Int J Artif Organs 2008; 31: 683-696.

6. Peters MG. Special populations with hepatitis B virus infection. Hepatology 2009; 49(5 Suppl), S1: 46-55.

7. Arankalle VA, Chobe P, Banerjee K. HCV in Pune. J Assoc Physicians India 1992; 40: 562.

8. Baur P, Daniel V, Pomer S, Scheurlen H, Opelz G, Roelcke D. HCV in kidney recipients: epidemiology and impact on renal transplantation. Ann Hematol 1991; 62: 68-73.

9. Bruguera M, Vidal L, Sanchez-Tapias JM, Costa J, Revert L, Rodes J. Incidence and features of liver disease in patients on chronic hemodialysis. J Clin Gastroentrol 1990; 20: 5042-5045.

10. Sato S, Fujiyama S, Tanaka M, Yamasaki K, Kuramoto I, Kawano $\mathrm{S}$ et al. Co-infection of hepatitis $\mathrm{C}$ virus in patients with chronic hepatitis B infection. J Hepatol 1994; 21: 159-166.

11. Pontisso P, Gerotto M, Benvegnu L, Chemello L, Alberti A. Coinfection by hepatitis $\mathrm{B}$ virus and hepatitis $\mathrm{C}$ virus. Antivir Ther 1998; 3(Suppl): 137-142.

12. Sumathy S, Valliammai T, Thyagarajan SP, Malathy S, Madanagopalan N, Sankaranarayanan VS. Prevalence of $\mathrm{HCV}$ infection in liver diseases, renal diseases and VBDs in South India. Indian J Med Microbiol 1993; 11: 291-297.

13. Wong $\mathrm{P}$, Mak S, Wong AK. Management of chronic hepatitis $\mathrm{B}$ infection in patients with end-stage renal disease and dialysis. Hep B Annual 2006; 3: 76-105.

14. London WT, Drew JS, Lustbader ED, Werener BG, Blumberg BS. Host responses to hepatitis B infection in patients in a chronic hemodialysis unit. Kidney Int 1977; 12: $51-58$.

15. Martin P, Friedman LS. Chronic viral hepatitis and the management of chronic renal failure. Kidney Int 1995; 47: 1231-1241. 
16. Allain JP. Occult hepatitis B virus infection. Transfus Clin Biol 2004; 11: 18-25.

17. Sit D, Kadiroglu AK, Kayabasi H, Yilmaz ME, Goral V. Seroprevalence of hepatitis B and C viruses in patients with chronic kidney disease in the predialysis stage at a university hospital in Turkey. Intervirology 2007; 50: 133-137.

18. National Kidney Foundation. KDOQI Kidney Disease Outcome Quality Initiative. Am J Kidney Dis 2002; 39: S1-S266.

19. Registry of the Nephrology, Dialysis and Transplantation in Turkey. Registry, 2004.

20. Akpolat T, Arik N, Gunaydin M, Utas C, Dilek K, Caglar S et al. Prevalence of anti-HCV among hemodialysis patients in Turkey: a multicenter study. Nephrol Dial Transplant 1995; 10: 479-480.

21. Dundar IH, Inal AS. Viral hepatitis from past to today. In: Tabak F, Balik I, Tekeli E (eds). Viral Hepatitis 2005 (in Turkish). Istanbul, Society of Struggle against Viral Hepatitis Publication 2005: 10-20.

22. Hepatitis B: 2008. Available at: http://www.who.int/ mediacentre/factsheets/fs204/en. Accessed December 2015.

23. Islam MN, Islam KM, Islam N. Hepatitis-B virus infection in Dhaka, Bangladesh. Bangladesh Med Res Counc Bull 1984; 10: 1-6.

24. Rumi MA, Begum K, Hassan MS, Hasan SM, Azam MG, Hasan $\mathrm{KN}$ et al. Detection of hepatitis B surface antigen in pregnant women attending a public hospital for delivery: implication for vaccination strategy in Bangladesh. Am J Trop Med Hyg 1998; 59: 318-322.

25. Mustafa M, Islam MN, Rahman M, Salauddin AK. Prevalence of hepatitis B surface antigen (HBsAg) among parenteral drug abusers at Dhaka, Bangladesh Med Res Counc Bull 1989; 15: 1-7.

26. Ahmad Q, Chowdhury SG, Islam MN, Khan FD, Alam MR, Miah AH. HBsAg amongst unscreened operated patients. Bangladesh Med Res Counc Bull 1991; 17: 11-16.

27. Sattar H, Islam MN. Hepatitis B virus markers among the prostitutes of Dhaka. Bangladesh Med Res Counc Bull 1996; 22: 8-11.

28. Mahtab MA, Rahman S, Karim MF, Khan M, Foster G, Solaiman $S$ et al. Epidemiology of hepatitis B virus in Bangladeshi general population. Hepatobiliary Pancreat Dis Int 2008; 7: 595-600.
29. Ashraf H, Alam NH, Rothermundt C, Brooks A, Bardhan $\mathrm{P}$, Hossain $\mathrm{L}$ et al. Prevalence and risk factors of hepatitis $\mathrm{B}$ and $\mathrm{C}$ virus infections in an impoverished urban community in Dhaka, Bangladesh. BMC Infectious Diseases 2010; 10: 208.

30. Islam MN, Hossain RM, Rahman MH, Mansur MA, Hassan MS, Islam MS et al. Hepatitis B (HBV) and C (HCV) among maintenance hemodialysis patients, family members and dialysis staffs. Abstract from $27^{\text {th }}$ Annual Dialysis Conference. Hemodialysis International 2007; 11(1): 108.

31. Ahmed B, Grover R, Ratho RK, Mahajan RC. Prevalence of hepatitis B virus infection in Chandighar over a six years period. Trop Gastroenterol 2001; 22: 18-19.

32. Chattopadhyay S, Rao S, Das BC, Singh NP, Kar P. Prevalence of transmitted virus infection in patients on maintenance hemodialysis from New Delhi, India. Hemodial Int 2005; 9: 362-366.

33. Yakaryilmaz F, Gurbuz OZ, Gulter S, Mert A, Songur Y, Karakan T. Prevalence of occult hepatitis B and hepatitis C virus infection in Turkish hemodialysis patients. Ren Fail 2006; 28: 729-735.

34. Shahin S, Khoybar A, Farhana A, Matira K. Evaluation of the antibody response against hepatitis $\mathrm{B}$ virus infection in patients on maintenance hemodialysis: a pilot study. Bangladesh Journal of Medical Science 2009; 8 (1-2): 15-22.

35. Alavian SM, Bagheri-Lankarani K, Mahdavi-Mazdeh M, Nourozi S. Hepatitis $\mathrm{B}$ and $\mathrm{C}$ in dialysis units in Iran: changing the epidemiology. Hemodial Int 2008; 12(3): 378-382.

36. Lalazar G, Rund D, Shouval D. Screening, prevention and treatment of viral hepatitis B reactivation in patients with haematological malignancies. Br J Haematol 2007; 136: 699-712.

37. Loomba R, Rowley A, Wesley R, Liang TJ, Hoofnagle JH, Pucino F et al. Systematic review: the effect of preventive lamivudine on hepatitis $\mathrm{B}$ reactivation during chemotherapy. Ann Intern Med 2008; 148: 519-528.

38. Grob P, Jilg W, Bornhak H, Gerken G, Gerlich W, Gunther $\mathrm{S}$ et al. Serological pattern 'Anti HBc alone'. Report on a workshop. Journal of Medical Virology 2000; 62: 450-455.

39. Knöll A, Hartmann A, Hamoshi H, Weislmaier K, Jilg W. Serological pattern "anti-HBc alone", characterization of 552 individuals and clinical significance..World J Gastroenterol 2006; 12(8): 1255-1260. 